\title{
Local Government: Getting the South African Municipal Finances Right
}

\author{
Gezani Mazibuko \\ First Choice Achievers Learning Centre NPO (ZA) \\ gezanimazibuko@gmail.com, hlohlo@lantic.net
}

\begin{abstract}
Local government in South Africa from Musina to Cape Town have faced strategic financial management challenges of budget shortfalls, financial shambles and distress, leading to unmaintained infrastructure, deteriorating services quality, increasing municipal deprivation and intensifying social exclusion which is the unfortunate history of many municipalities. Municipal effective control leads to design, muster and fiscal wealth may accumulate effective approaches that accomplish its duty to be answerable to its inhabitants. Financial control and stewardship are preceded by the interconnected management facets towards augmenting the growing design, catalytic and hands-on route. Financial control is facilitated by effective reporting and auditing is chiefly paramount for accountability in the local government environment. Weak municipal management accountability and oversight institutions prevailing in local government compromise its integrity and a potential loss to the public's confidence. Local government is confronted, by municipal fiscal administration morass and forgone fiscal reserves. The efficient budget implementation should conform to the will of the legislature's authorizations. The financial position of municipalities in terms of the business model represents assets, liabilities and equity and displays the financial health at a specific time. The community and major stakeholders use financial statements to determine the financial position of any organization. The financial position and health determine how efficiently a municipality is expanding its resources and investment. This paper seeks to close the gap that other studies have not ventured to. This paper qualitatively and descriptively explores municipal financial management enigma and proposes a turnaround to get local government finances right.
\end{abstract}

Keywords: Local government, financial management, municipal administration, resources, investment.

\section{Introduction}

Globally, local governments are under increasing economic force to do extra with fewer resources (Farvacque-Vitkovic and Kopanyi, 2014). The local Government in South Africa accomplishes well in financial controlling as compared to other emerging countries. According to (IIAG) (2018) (from 2008-2017), South Africa ranked 7th and score 68 percent out of the 54 countries in Africa (Mo Ibrahim Foundation, 2018). The Global Competitiveness Report 2018 ranked South Africa 67or a score of 60.8 of 140 (World Economic Forum, 2018) countries as opposed to 61 (2017/18). Undoubtedly, local government should learn from its financial management mystery, improve from the report and strive for excellence in financial management effectiveness and efficiency. Resilient local government financial controls are a fundamental driver for both productivity and long-term growth. Local government financial benefits extend well beyond economics, affecting people's well-being on daily basis (World Economic Forum, 2018) in many municipalities. The plague of financial management syndrome signifies weak institutions in the history of democratic South African local government after a mere 26 years of ushering into this important phenomenon and an era.

Is it a huge achievement, an extraordinary hype for a brand New Mandela South Africa democracy and something to celebrate eloquently and confidently? Indeed the financial management in local government portrait a state of morass and financially ill health. From Musina to Cape Town, most municipalities have financial restraints regarding financial control, accountability, and grants dependence, non-payment of services culture, outstanding debts and governance. Municipalities are more and more reliant on intergovernmental allocations, which have been dwindling over time, in part because of the financial burden generated by the worldwide monetary degeneration, sluggish revenue collection generation and deteriorating economic growth and Covid-19 pandemic (Farvacque-Vitkovic and Kopanyi, 2014). Local government finances are customarily adequate to fund municipals' working expenditures but not much on desirable major investments. Paradoxically, how can municipalities create reserve further than allocations, is critical for increasing financial wealth in local government? Municipal officials have to be ardent, use, incorporate fiscal controlling philosophies and apparatuses to device their overheads, recognize innovative income foundations, and expand the local tariff pool. 
For those municipalities that are in healthier economic nature, augmenting their wealth and cautiously gain access to investment market places offer prospects for insightful transformation. Certainly, upgraded control practices and heightened answerability instruments developed are vital to all-encompassing community fiscal controlling. The significance of this paper is to assist the community, practitioners, accounting officers and authorities, policymakers in provincial, national and municipal administration to appreciate the need for effective and efficient financial management, to have a discourse and get the municipal finances right in the next decade. This research is paramount as municipalities have to ensure sufficient fiscal reserve and effective financial oversight.

\section{Literature Review}

Various dynamics position and hip the way of enlarged fiscal revenue deployment in local government. Local governments have inadequate lawful taxing power (Bahl, 2012). Local governments also often underuse the taxing power that they have and as such results in the fiscal administration conundrum. The conceptualization of the municipal financial management is underpinned by iconic financial management, capital and operating budget, municipal financial plan, financial overruns/over expenditure, assuring financial compliance, financial reports, and oversight-after party. The above issues are central to the financial management literature review process in this research.

Financial Management: According to (Mazibuko and Fourie, 2013b) municipal financial management is preceded by the interconnected management facets towards augmenting the growing budget design, catalytic and hands-on route. Arguably, such budgetary process enables growth for capital investment for infrastructure development, maintenance of and repairs to existing infrastructure and generating revenue. Local authorities pursue sustenance on how to plan and achieve significant reserves and formulate fundable developments. Fiscal administration is a vital constituent of public organization and more specifically municipal administration. It empowers the local authorities to streamline, activate, and utilize resources in a proficient and active mode, as well as accomplish its commitment to be held responsible to its inhabitants. Municipal financial management predominantly mirrors four pillars namely: budgeting or financial plan, accounting, financial reporting and auditing (Shah, 2006). The fundamentals of the municipal finances practice are strengthened by the machinery of municipal subdivision monetary administration such as allocations, bookkeeping, information, and auditing, and their submissions in municipal administration. 
Figure 1: Pillars of Municipal Financial Management

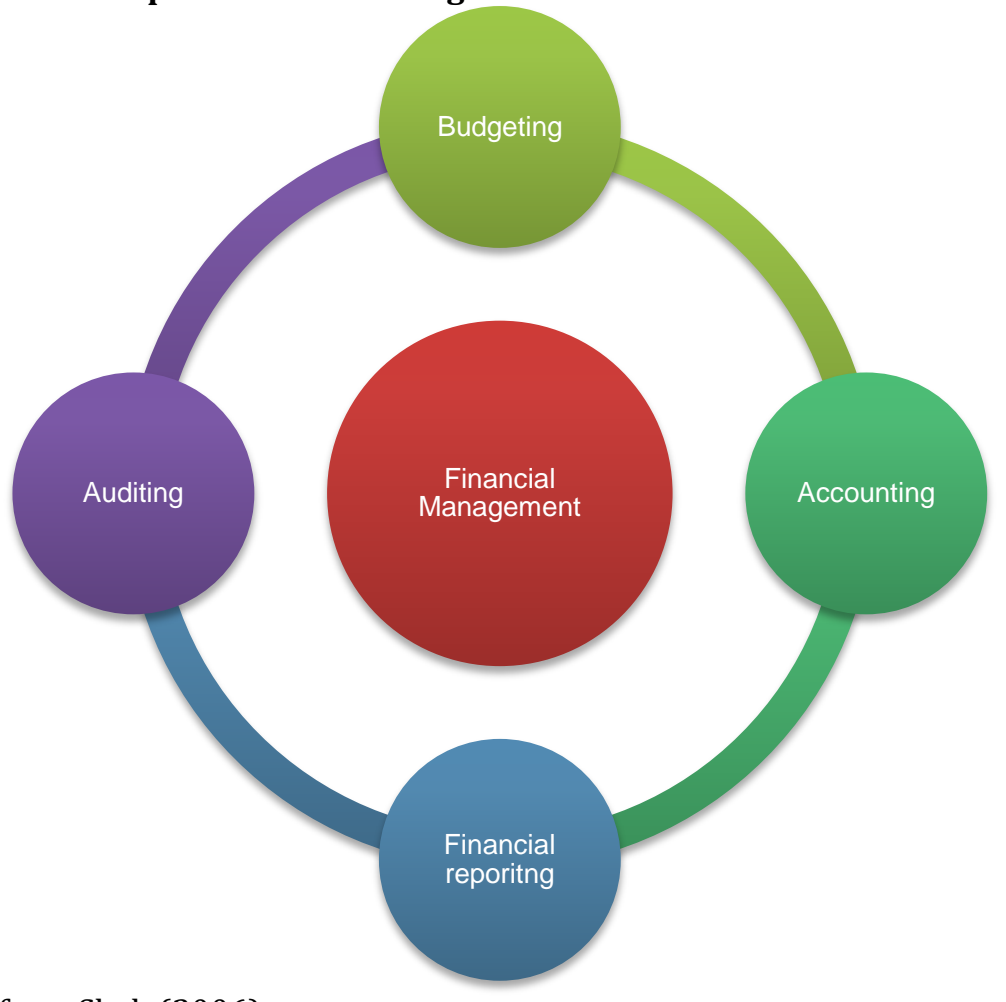

Source: Adapted from Shah (2006)

Capital and Operating Budget: The MFMA (Municipal Finance Management Act) directs that an annual financial plan must largely be allocated into capital and an operating budget (South Africa, Republic, 2003). Municipalities draft budgets yearly and that is preceded by a service delivery improvement plan and thus service delivery follows. Municipal budgets comprise operating budget, capital budget, operating income and expenditure. The municipal financial plan is a plan for the municipality to follow succinctly according to the predetermined budget cycle (Mazibuko and Fourie, 2013b). The municipality must compile determination approving the financial plan, striking civic levy and locating charges for that specific year. The municipality has to quantify routine goals for income from each basis and division in the financial plan, captivating into description the municipality's incorporated improvement plan. Without a forecast of each cash flow for the economical classification by income foundation and apportioned it per month will influence the task. Such a financial plan should give specifics of public reserves.

In both coherent and sequential categorization, the central phases in the budget planning development progress from the explanation of the macroeconomic and financial structure to the question of financial, plan guidelines, planning of budget plans, debates on those plans, and then arrangement to and authorization by the governing body (Shah, 2007). Three main circumstances are required for the anticipated result of a budget that is both precisely comprehensive and authentic to dogmatic commands: enchanting an intermediate duration standpoint, building early pronouncements, and set an unbreakable control. To be a real tool of fiscal administration, the municipal budget must without hook or crook is a trustworthy instrument. To be dependable, the disbursement plan must be inexpensive (Shah, 2007). Therefore, financial planning should be evaluated on a monthly and quarterly basis to ensure that what revenue is budgeted for is still on course. The state of affairs should take into account that the revenue approximation may change before the budget is concluded and of course to produce a dependable revenue-expenditure compendium.

Municipal Financial Plan: Mazibuko and Fourie (2013b) allude that without financial resources municipalities cannot deliver services to the community. To this end, there would be a need to exploit sufficient revenue through by raising taxes, levies, rates and service changes from the inhabitants. The procedure is to put a budget or a financial plan in place and package the requirements according to financial 
management norms and standards. Organizing the budget or municipal financial plan necessitates indestructible adoptions. These pronouncements are a charge driven, circumvented, at countless fees. The necessary interchanges must be made unambiguously when articulating the budget. This will result in a horizontal application of significance platforms, thwart interference and budget package administration accomplishment. Dogmatic intervention, managerial feebleness, and the dearth of required evidence frequently prime to rescheduling these durable ranges until budget implementation. According to (Simson, Sharma, Aziz, 2011), the various municipal procedures are designed in the financial plan phase. Such a yearly progression targets safeguarding public disbursement is a healthy prearranged implementation and accounted for. Hashim (2014) postulates that financial planning starts with the development of a circular demonstrating profitable prospect. The preparation is also comprehensive program intentions.

On how the financial plan is estimated to accomplish goals and sectoral apportionments and limits dependence with the macroeconomic structure. The financial planning or budgeting procedure is vibrant in setting out the municipality's prime of disbursement significances and classifying the funds indispensable for the apprehension of strategic overheads. Budgeting and resources are vibrant in the forecasting, control, and assessment of regime maneuvers. The financial arrangements and development make available moderate for formative what administration facilities will be provided and how they will be funded. The budget helps for the attainment of municipal objectives goals. The budget as a financial tool is compiled using monetary and other pertinent demographic data. Monetary data includes the approximations of resources, what is available and required to accomplish recognized essentials, while other sources of information entails public priorities, policy, and political considerations. The financial plan implementation is the phase whereby means are utilized to apply policies integrated with the plan. Good financial plan groundwork comes first, lucidly and chronologically. Municipal administrators should categorically understand that financial planning procedures are not originated simply instruments for warranting compliance with the original program design.

Financial Overruns/Over Expenditure: The internal and management control function in any municipal capacity is paramount, fundamental and without it, the pillars of financial management would be twisted (Mazibuko and Fourie, 2013). Fiscal plunders should be steered off of contradiction at all the intervals. Disbursement control applications on guaranteeing that funds are allotted and used to accomplish approved primacies are imperative. Besides, the evidence would be presented to qualify municipality to organize and screen the performing of their plug-ins and the bearing of their outflows. The material outfits comprise an arrangement of resources and outflows, apportioning or appropriating incomes and relocating resources and purposes, governing and achieving costs and the announcement of money and checking spending enactment (Farvacque-Vitkovic and Kopanyi, 2014). The assurance point is once an imminent commitment to pay is sustained. The commitment phase is paramount in monetary controlling, as expenditure decisions become effective.

Certainly, overruns are triggered by non-compliance with the expenditure parameters distinct in the financial plan, once expenditure is committed. Overruns shot into debts cohort, the effect thereof is off-budget outlay contrivances e.g. outflows from unusual, "below-the-line" of the account items. In certain municipal environments, spending procedure may be cumbrous, "unique techniques" are fashioned to side-step them. Deficiency in compliance may be overcome by solidification inspection structure, bolstered by reporting and co-ordination. In addition, guaranteeing the value of the rudimentary fiscal performance gearshifts should be considered part of the financial planning (Shah, 2007). The CFO (Chief Financial Officer) must appraise any directive or draft pronouncement that can have a financial bearing. Arguably, Chief Financial Officer may plunder; and knee-jerk appropriating developments. Comprehensive financial planning procedures and satisfactorily established measures are a precondition to circumventing plunders. However, in certain municipal environments with unscrupulous supremacy, pursuing resolutions on the procedural flank might be deceptive.

Assuring Financial Compliance: The CFO must take a pronouncement to transmit a program sanctioned in the financial plan. The rudimentary compliance gearshifts during financial planning related to the commitment phase. Certainly, financial imperative corroboration through proposals may expend budget that is ratified by a lawful official and adopted for the single-mindedness in the budget. Besides, it should ensure that sufficient funds are remaining available in the suitable grouping of spending. Further, the spending is 
projected under the right grouping (Shah, 2007). Any non-compliance should be reported to the provincial treasury for intervention. Mazibuko and Fourie (2013b) posit that the stakeholders should ensure accountable employment, compliance and proprietorship of the structure of internal and management controls.

Financial Reports: Expenditure proposals and revenue forecasts and financial analysis will follow once the budget is finalized. Financial reporting and auditing are fundamental in local government (Mazibuko and Fourie, 2013b). The analysis of reports is done monthly pursuant section 71 of the MFMA whereby actual revenue, borrowings, expenditure, capital expenditure amount of any allocations received which are related to actual expenditure, material variances, remedial or corrective steps, projections of revenue and expenditure and any information of the state of budget are put (South Africa, Republic, 2003). Simson, Sharma and Aziz (2011), hypothesize that financial reports are aimed at cultivating budget compliance. They deliver wealth for internal or external actors to evaluate management routine. Pecuniary account and reporting demand mining and offering records from the bookkeeping system in traditions that expedite inquiry. Municipal administrations harvest an assortment of intelligence in the form of reports for internal and external assimilation. The Accounting Officer in the council must after 10 days of the month ending submit a monthly budget statement evaluating the budget implemented (South Africa, Republic, 2003). The Accounting Officer must provide a mid-year budget and performance assessment report as per the municipal budget statement. The report should also state failure if any and reported to Provincial Treasury and ultimately to National Treasury. There the implementation of oversight reports on annual reports cannot be overemphasized.

Oversight-After Party: Oversight is paramount in the financial management environment cycle. This can be applied through Council, Municipal Mayor, Municipal Executive Committees; Portfolio Committees especially the Municipal Public Account Committee, Finance committee should put their hands on the deck. The submission, auditing of annual financial statements, annual reports and monitoring thereof are the ingredients for municipal financial management safe nirvana, hegemony and dynasty. The Auditor-General is a Chapter 9 constitutional body autonomous of the government with the supremacies to examine government transactions, structures and practices. Mazibuko and Fourie (2013b) assert that financial audits are designed to detect problems in the system of internal control, adherence to reporting standards and anything matter thus results in misappropriation of funds.

Auditing is a valuable mechanism and the procedure of autonomous authentication of the accounts and monetary information. Auditing provides assurance to external persons and bodies around the trustworthiness of the municipal financial data. Auditing is liable for the examination and analysis of municipal pecuniary, ensure compliance and assurance to the municipality. In addition, the need for continuous municipal government audits is to guarantee the economic usage of municipal coffers in harmony with largely regime priorities (Hashim, 2014). Simson, Sharma and Aziz (2011) posit that external auditing is the critical compliance mechanism in municipal government. External auditing so designed when implemented in harmony with the legislation may deliver municipal amenities according to the wishes of the electorate.

\section{Research Method}

This study used qualitative research to identify and collected secondary sources of information to explore the local government's financial challenges and opportunities. To this end, various books, journal articles and government reports were collected for this study.

\section{Discussion}

Local government revenue is self-generated. The sources are from property taxes and services to businesses and ratepayers cum residents. There are two main sources of revenue namely: own revenue and intergovernmental fiscal transfers (Mazibuko, 2013a). These two components in the main form a greater chunk of financial management. Despite the above all-encompassing organization, the financial health in the municipal government has circumnavigated to a locus of nimble state orchestrating and designing the institution to a huge loss of public confidence in municipal governance. The state of financial mismanagement 
is widespread in the South African Municipal administration. The spending of more than the resources available at their disposal and that result in budgets those are unfunded. Municipal revenue streams are continuing to be less resistant and growing in harmony with the population growth of the municipal environment. The revenue growth conundrum is in the main caused by the non-elasticity of the revenue regimen. The political will to enforce, collect and exploit revenue from residents fully lead to high implementation of intergovernmental transfers or grants in local government.

The state of affairs is grant dependency in local government leads to financial management morass. The "culture of non-payment (Financial and Fiscal Commission, 2020) increases the financial management generally and specifically the municipal revenue mystery in municipal governance. The culture of nonpayment in question surprisingly happens even to national and provincial governments not wanting to pay water and electricity rates and taxes accruing for local government. How do we then expect the municipalities to grow and be financially viable and autonomous in that kind of environment? Quite unlikely! Right/wrong? The local government in South Africa's financial management needs to be put right. The discussion on putting the municipal finances rights will focus on municipal planning and budgeting, local revenue management, municipal governance, budget Implementation, municipal financial position, creditors' management and municipal fiscal sustainability. The selected issues are paramount to assist in helping the local government put her finances right.

Municipal Planning and Budgeting: In municipal administration, planning and budgeting is an annual ritual. If the incompatibility of the different roles of planning and budgeting were not sufficient, more recently these problems have been exacerbated by events in that municipalities use budgeting systems to integrate everything. The increase in global competition is also putting pressure on municipal administration (Bourne, 2005). If dealing with the external market changes is not in itself, there are new management paradigms, reporting and regulatory requirements to deal with. The stakes from getting the budget wrong are getting higher. There is a move towards quarterly reporting, putting pressure on municipal councils to meet financial results quarterly and forecast more frequently. Municipal budget planning has to ensure a sufficient plan for infrastructure management, operations and maintenance.

Local Revenue Management: Mazibuko (2013a) refers that self-sufficient revenue collections are an organizational reform in municipalities. The municipality tax base in the context of the economic and social environment and legislative environment is paramount in the municipal administration. Municipal revenue has historically been introduced for purposes of financing municipal infrastructure development and services. Certainly, an excellent financial management system should be preceded by a set of high standard principles of revenue exploitation. The principles can be categorized as vertical equity, horizontal equity, and ability to pay principle, economic principle, financial principle, efficiency principle, simplicity principle, beneficiary principle and enforceability principle. It goes without saying that services should be financed by beneficiaries/residents/property owners (Shah (2006)) in terms of the general benefit principle, directly or indirectly (Slack, 2009). What is prevalent in municipalities is constraining funding for infrastructure development is the culture of non-payment of municipal services. The cause for the intensification in defaulters among households is connected with fragile income collection (South Africa, Republic, 2019). Shah (2006), states the application of payments is paramount in revenue collection.

What is also apparent in municipalities is the fragile prosecution which is instigated by the non-existence of consequences for non-compliance with legislation. Deprived revenue prosecution may be due to factors such as the absence of answerability; deficiency of political willpower to exploit and administer revenue collection; frail established and organizational capacity, a dearth of inducements, absence procedure in promulgation revenue, disbursement casualness associated with dishonesty. Dearth impedes leaders on how countless taxpayers are omitted from their revenue master files, In addition, how many of those who are registered are listless, and how much is actually being avoided in tax payments. Certainly, even when taxpayers are documented and enumerated and lively, sometimes there is no complete and reliable evidence on their tax charges, tax payments made, and their balances. Such revenue remains irrecoverable debt for the municipalities and would stay in the debtors' book for over 120 days. Land tax and environmental taxes on the illegal cutting of trees in the rural areas and damaging the environment are some areas where such exploitation of revenue can be considered (Mazibuko, 2001). 
Certainly, some taxes can be strategized in the municipal revue business model. Local business tax is another revenue source resilient than, for example, property taxes. Vehicle and conveyance taxes are revenue sources worth exploitation. Natural resource taxes with regards to fishing opportunities, quarrying, mining, molding of bricks in the rural areas, in particular, can generate revenue for the local government. Improvement on and construction: This is one area where revenue can be generated that can add an impetus for the growth of income of local government (Financial and Fiscal Commission, South Africa, 2020). Land-based revenue may be exploited in South Africa as they are appropriate for investment, especially from infrastructure development. The land is an instrument to be leveraged to finance local infrastructure development. Municipalities in North America levy development charges on developers which augment funding for infrastructure development (Un-Habitat, 2009). For good governance proper, financial plan execution structure must ensure amenability with fiscal sanctions.

Municipal Governance: The Weak municipal financial management accountability and oversight institutions prevailing in local government do not bring sustenance to municipal administration. Good governance is an armament that can save the local government from monetary anguish and unwholesome pecuniary atmospheres. Shah (2007) posits that, relates to answerability, predictableness, and membership. Answerability is a critical dimension for municipal administrators to be accountable for their actions. These theories are collective in the claim but comparative in the landscape. Answerability is an obligation, but it does not convert working pending one outlines answerability of whom, for what, and to whom. To this end, complete compliance by means of guidelines is not sufficient if the guidelines are ineffective and do not involve community members (Shah, 2007). In an endeavor to steer a people's socio-politico-economic development, governance is a multidimensional complex state of establishments, organisms, organizations, procedures, actions, practices, associations. Management performance in the implementation of social, political, economic, and leadership power in municipal administration is also paramount. Involvement of communities, listening to concern, as the powerful dynamism is a sign of good governance (Kauzya, 2003). Local government is confronted by municipal fiscal administration morass. Simson, Sharma and Aziz (2011) state that municipal financial management triggers all regime bustle. It embraces the deployment of income; the distribution of these resources to countless accomplishments; disbursement; and accounting for expended funds. Financial management execution calls for the budget to be employed in orthodoxy approved in the legislation.

Budget Implementation: The efficient financial plan implementation demands that the budget conforms to the will of the legislature's authorizations. The state of affairs should be in line with changes in budget program implementation that is managed efficiently, preventing any threat of exploitation and fraud (Shah, 2007). Simson, Sharma and Aziz (2011) assert that to gain any thoughtfulness on how resources were utilized should be through monitoring of expenditure results and proper implementation processes. According to Hashim (2014) the budget implementation, through well-thought accounting and financial reporting functions is tied to a financial plan or budget. The budget or financial plan dictates that municipalities should deliver the services that citizens have demanded. Such an action should be through choices made in a democratic process of public participation. Certainly, the available resources should be implemented efficiently and economically. Financial plans are tools of monetary self-restraint and control mechanism used by both the policymakers and the governmental divisions of a local government (Shah, 2006).

The budget for repairs and maintenance spending should be scrutinized by movement on monthly basis, and industrial endorsements. Municipalities undergoing pecuniary hassle repeatedly pursue to instantaneously decrease overheads on maintenances and upkeep as its influence is not directly noticeable (South Africa, Republic: National Treasury, 2018). Local government experience budget under-spending year in year out in the number of municipalities. The under-spending problematic distresses the endorsed financial plan and, predominantly, its infrastructure expansion budget. Certainly, under-spending is linked to inadequacies in planning. To this end, overrated financial plans and impracticable forecasts of incomes are central to redesigning the budget throughout budget implementation. Arguably, when a financial plan is poor, inefficiencies in budget planning are addressed through monotonous financial arrangements. Under-spending replicates meager planning; save with unforeseen events such as natural disasters (South Africa, Republic: National Treasury, 2018). 
Municipal Financial Position: The financial position of municipalities will normally represent assets, liabilities and equity, displays the financial health of the municipality. When diagnosing the reasons that contribute to the municipal liquidity challenges it is prudent to holistically examine the organizational and operational management inefficiencies. The causes related to organizational factors including mismanagement, transparency and public administration and other political factors. Organizational factors are relatively easier to resolve because they are often internal to the organization. The financial statements of a municipality show how it spends its money, where its revenue comes from, its assets and the state of those assets, how much it owes creditors, how much is owed to the municipality (South Africa, Republic: AuditorGeneral of South Africa, 18). Challenges are also experienced with enforcing debt collection and an increase in the aged debts, inadequate collection of service charges and culture of non-payment, poor compliance and inefficient collection of revenue (Fjeldstad, 2004), resources and managing in municipal government during fiscal crises.

The worrying and pathetic factor is that some municipalities are unable to pay salaries to 1,670 councilors, traditional leaders and all staff for four months. The municipality is in financial distress wants R330m more to cover for salary crisis and layoffs (Soyiso Maliti and Daily dispatch, 14 January 2021). Certain challenges have been exacerbated by the recession and financial shortfalls (Jacobson and Sowa, 2016). Liquidness encounters are the most shared exhibition of pecuniary misery in municipalities. Municipalities with liquidity encounters fail effectively to providing amenities, billing for services and collecting the revenue owed to them. A municipality must have sufficient reserves to provide its monthly fiscal obligations and commitment. Cash and liquidness glitches force result in a municipality with helpless exposure cash situation. Many municipalities experience impermanent complications. The reserve equilibrium balances a solid pointer of unembellished principal fiscal difficulties (South Africa, Republic: National Treasury, 2018).

Creditors' Management: Creditors' management is vital in financial management environments. Mazibuko and Fourie (2013b) postulate critically on creditors and accounts payable that remain unpaid after 30 days of the date of the invoice due to cash flow problems. Apparently, municipalities do not comply with the MFMA and that their cash flow administration is scrawny as creditors are not paid within the limits set in the procurement legislation. National and provincial governments provide capacity and certain interventions to assist municipalities to hit the ground running. However, despite this support municipalities continue to façade through fiscal organization watershed. Arguably, the deficiency of steadiness and organized compliance in organizational governance can taint the fiscal well-being of a municipality and thus public confidence (South Africa, Republic: National Treasury, 2018). Creditors are important stakeholders in the procurement authority as they provided services to the government. Certainly, an unrealistic budget can be the cause for this unfortunate state of affairs, and ultimately affect municipal integrity and hence dwindling in public's confidence in local government. Performance indicators on spending should be well-matched with financial limitations and be prearranged in the planning cycle.

Municipal Fiscal Sustainability: Arguably, South African municipalities are insufficiently fiscal sustainable. Local governments need fiscal reserves to manage fluctuations in revenues and spending without disrupting the provision of infrastructure development and services (Gorina, Maher \& Park, 2019; Guo and Wang, 2017). To ensure municipalities remain going concerns, able to sustain existing services and progressively extend services, they need to ensure that the municipal budget is funded in accordance with legislative imperatives. Effective fiscal sustainability indicators have to assist municipalities as measures of the financial flexibility of municipalities. Certainly, the fiscal sustainability measure indicates the capacity of a municipal organization to respond to changing circumstances and that encompass the adverse financial shock. The liquidity of a council is very much important in the financial environment, financial standing and stability of the council (Ryan, Robinson \& Grigg, 2000). Arguably, in the implementation phase, there would be no adequate techniques that exist. Such an arrangement of a measure should be able to measure the municipal council's ability to pay its short term commitments and providing a status of the viability of the council in the long term. 


\section{Conclusion and Recommendations}

Despite several financial management reforms that took place in South Africa's local government since the dawn of democracy, municipalities are still faced with financial management conundrums. The major fiscal policy question to be addressed is how the alternative revenue to cover the shortfall will be found. However, there is a need to respond to financial management mystery that will focus on the unending riddle in financial management in local government. The public's confidence is dwindling day in and day out, this paper calls for government practitioners and policymakers across the board to be pained by what is transpiring in local government in general and specifically financial management and then take a break and take stock of the suggestions in this novel article. There is a need to sign a pledge and say enough is enough and ensure that things are indeed turned around for the good of future generations 100 years to come. The following are proposed for the local government financial management policy shift.

Financial Management Policy Alternatives: South African local government needs skills in strategic financial management positions at all levels. South Africa is part of the global world; municipalities should be considered business investment institutions. Certainly considering the alternative sources of revenue on an on-going basis is something needing a paradigm. Natural resource taxes with regards to fishing opportunities, quarrying, mining, and molding of bricks can generate revenue for the local government. Improvement on and construction is one area where revenue can be generated that can add an impetus for the growth of income of local government. Benefit charges can increase revenue potential in municipalities especially those levied on land. Municipalities could be empowered to levy the transfer tax on real property. Land tax and environmental taxes cutting of trees in the rural areas and damaging environment Local business taxes are another revenue source. Vehicle and transportation taxes-are revenue sources worth exploitation. Landbased revenues to finance local investment should be viewed as an investment. Public-private partnerships between municipalities and a private sector party can enhance the funding capacity of municipalities. This research calls for improvement in planning and budgeting processes. There is a need therefore to decouple the achievement of the budget from the compensation process. Decouple the budgeting and forecasting process.

Budgets are concerned with resource allocation and as such require management input and negotiation and forecast can be done using financial models. Use external benchmarking to set cost control targets. Certainly, financial targets are easy to manipulate, therefore set direction using both financial and non-financial performance measures. Improving the financial position can be done in the short run by reducing service levels and competitiveness. It is imperative therefore to build explicit links between the major non-financial activities and resulting performance and then manage the change in these relationships. Certainly, the fiscal exchange cannot be overemphasized in that compliance on the payment of services for example can be motivated by the presence of government expenditures. Residents may pay for service changes because they value the goods or infrastructure paid by municipalities, recognizing that their payments are necessary both to help finance infrastructure development. It should be borne in mind that fiscal exchange requires the trade-off gains that may be seen as a prerequisite of voluntary compliance. The existence of positive benefits, measured according to quantitative and qualitative criteria, may increase the probability that ratepayers will comply voluntarily without direct coercion. There is a need to consider fiscal sustainability which has a capacity of the organization that can meet present and future levels of debt and financial obligation. That has to be supported by the municipality's revenue constraints.

There is a need for municipalities to have a fiscal reserve in revenue and spending which may be driven by the financial management practices of the neighbors, shared environments. Certainly, fiscal sustainability measures should encompass own revenue reliance, revenue flexibility/intensity, indebtedness and liquidity. There is to get the basics of cash management and revenue management right. The relationship between financial planning and effectively managing municipal cash resources and ensuring regular bank reconciliations of municipal accounts are undertaken. In respect of revenue management, it means paying attention to the integrity of billing information, the accuracy of bills and having dedicated managers able to build administrative implementation systems that integrate each component of the revenue value chain. A careful balance will need to be struck between adjusting taxes and tariffs to cover the full, long term costs of service delivery and improved expenditure efficiencies. There is a need for the crop of Leadership acumen 
and strategists with a proven pedigree of running corporate without outstanding professional ethics. South African local government needs skills in strategic financial management positions at all levels. It can be through cadre deployment/political connected or whatever-the skills requirement. To do financial management work should be the key goal to gunner for effectiveness and efficiency and value for money.

Skills so required should amass sound and strong financial management capacity, strategic management capacity, and business acumen regimen just to cite few examples that could turn around the financial fortunes of municipalities. There is a need to strengthen local government budget execution systems. Amend legislation for large cities and accord them provincial and local government status. The local Government in South Africa may design an approach to address the municipal fiscal conundrum by moving large cities to state government status. The state of affairs may take away some of the roadblocks to increased revenueraising powers. To this end, it would resolve much of the local government fragmentation problem and thus restores her fiscal autonomy to the local government. To ease the financial distress in some of the municipalities, it would be imperative to design a new fiscal architecture that encompasses the city-state. The municipal area may have spread across jurisdiction boundaries so that the city-province status is assigned to the core city. The municipal government becomes a state in the province and have more manageable boundaries without the under structure of local governments to deal with. Based on the above, the local government would have turned the tide and finances may be put right.

\section{References}

Bahl, R. W. (2012). Metropolitan City finances in India: Options for a New Fiscal Architecture. International Centre for Public Policy Working Paper 12-33. Georgia State University. Andrew Young School of Policy Studies.

Bourne, M. (2005). Six steps to improving your planning and budgeting system. Centre for Business performance, Canfields School of Management, Canfields.

Farvacque-Vitkovic, C. \& Kopanyi, M. (eds). (2014). Municipal Finances A Handbook for Local Governments. Washington.D.C: World Bank.

Financial and Fiscal Commission. (2020). Technical Report Division of Revenue 2020/21: Repositioning Local Government Public Finances. Midrand: Finance and Fiscal Commission.

Gorina, E., Maher, C. \& Park, S. (2019). Toward a Theory of fiscal Slack. Public Budgeting \& Finance/Summer 2019.Dallas: Public Financial Publications, Inc.

Guo, H. D. \& Wang, W. (2017). A special Analysis of Florida County Governments's Unreserved General Fund Balances. Public Budgeting \& Finance, 37(3), 71-88.

Hashim, A. (2014). A Handbook on Financial Management Information Systems for Government-A Practitioners Guide for Setting Reform Priorities, Systems Design and Implementation (Based on a compilation of experiences in World Bank-financed projects). Washing D.C: World Bank.

Fjeldstad, O. H. (2004). What's trust got to do with it? Non-payment of service charges in local authorities in South Africa. Journal of Modern African Studies, 42(4), 539-562.

Jacobson, W. S. \& Sowa, J. E. (2016). Municipal Human Resources management: challenges and Innovative Practices in Turbulent Times. State and Local Government Review, 48(2), 121-131.

Kauzya, M. (2003). Local Governance Capacity-Building for Full-Range Participation: Concepts, Frameworks and Experiences in African Countries. Geneva: United Nations.

Mazibuko, G. P. (2001). Autonomy and Financial Viability of Local Authorities in the Limpopo Province. A Dissertation submitted in partial fulfilment of the requirement of the degree Masters of Business Administration. Buckinghamshire Chilterns University College. Buckinghamshire Business School in association with the Management College of Southern Africa (MANCOSA).Durban: MANCOSA.

Mazibuko, G. P. (2013a). The Impact of the Municipal Billing System on Revenue Collection in selected South African cities. Submitted in fulfilment of the requirements for the degree Master of Administration in Public Administration in the Faculty of Economic and Management Sciences. University of Pretoria.

Mazibuko, G. \& Fourie, D. J. (2013b). Municipal Finance: Relevance for Clean Aduit Outocmes. Administration Public, 21(4), 130-152.

Mo Ibrahim Foundation. (2018). 2018 Ibrahim Index of African Governance. Index Report.

Ryan, C., Robinson, M. \& Grigg, T. (2000). Financial Performance Indicators for Local Governments. Accounting, Accountability and Performance, 6(2), 89-106. 
Shah, A. (ed). (2006). Public sector governance and accountability series local governance in developing countries. Washington, D.C: World Bank.

Shah, A. (ed). (2007). Public sector governance and accountability series budgeting and budgetary institutions. Washington, D.C: The World Bank: The International Bank for Reconstruction and Development/Washington, D.C.

Simson, R., Sharma, N. \& Aziz, I. (2011). A guide to public financial management literature: For practitioners in developing countries. OVERSEAS DEVELOPMENT INSTITUTE.

Slack, E. (2009). Guide to Municipal Finance. The Human Settlements Financing Tools and Best Practices Series. Nairobi, Kenya.: UN HABITAT, Nairobi, Kenya.

South Africa, Republic. (2003). Local Government: Municipal Financial Management Act No 56 of 2003. Pretoria(ZA): Government Printers.

South Africa, Republic: Auditor General of South Africa (AGSA) (ZA). (2018). CONSOLIDATED GENERAL REPORT on the local government audit outcomes. MFMA 2016-17. Pretoria(ZA): AGSA.

South Africa, Republic: Auditor General of South Africa (AGSA)(ZA). (2019). CONSOLIDATED GENERAL REPORT on the local government audit outcomes. MFMA 2017-18. Pretoria(ZA): AGSA.

South Africa, Republic: National Treasury. (2018). The state of local government finances and financial management as of 30 June 2018. Fourth-quarter of the 2017/18 financial year. Pretoria(ZA): National Treasury.

Soyiso Maliti and Daily dispatch Reporters (ZA), 14 January 2021). Broke Municipality wants R330m more to cover salary crisis and layoffs.

UN-HABITAT (The Human Settlements Financing Tools and Best practices Series). (2009). Guide to Municipal finance. Nairobi: UN-HABITAT.

World Economic Forum (WEF). (2018). Insight Report: The Global Competitiveness Report. Geneva: WEF. 